\title{
Вплив структури на розподіл параметрів потоків і капілярне підняття води
}

\author{
В. А. Арсірій ${ }^{~}$, В. Ф. Ісаєв, П. М. Рябоконь, Б. Д. Савчук \\ Одеська державна академія будівництва та архітектури, вул. Дідріхсона, 4, Одеса, 65029, Україна \\ 1) $\square$ e-mail: arsiri.v.a@opu.ua, ORCID ID: https://orcid.org/0000-0003-3617-8487
}

\begin{abstract}
Візуальні дослідження руху рідини виявили структуру розподілу швидкості в поперечному перерізі. Виконано аналіз двох напрямків досліджень: ідей I. Пригожина пошуку зовнішніх сил для організаџіi структури або системи; а також гіпотеза М. Великанова про визнання форми існування матеріальних середовищ з притаманною їм самоорганізаџії когерентних або дискретних утворень. Виявлення структури потоків, стійкої в просторі $і$ часі, пояснює: чому навколишній світ демонструє високу ступінь організачії $i$ порядку всупереч домінування моделі хаосу турбулентності $i$ твердження про тендениії зростання ентропії. Гідравлічні експерименти довели вплив структури потоків на розподіл параметрів при русі рідин і газів. Коефічієнт гідравлічного тертя при заданих початкових параметрах залежить не тільки від числа Рейнольдса і шорсткості, але також залежить від поперечних розмірів каналу. Хвильовий характер розподілу параметрів отримано як при турбулентному, так $і$ при ламінарному режимах течії. Хвильовий характер зміни коефіцієнта гідравлічного тертя знімає проблему невизначеності розрахунку втрат напору та іниих енергетичних показників обладнання. Результати досліджень показують можливість формувати структуру потоку при русі рідин $і$ газів. До традиційних уявлень про параболічний закон розподілу епюри усереднених значень швидкостей додано хвильовий характер розподілу пульсаційних компонент швидкості. Підсумовування епюри усереднених значень ивидкості течї в кожній точияі потоків з хвильовим характером розподілу пульсаційних компонент швидкості дає епюру реальних значень швидкості в кожній точці поперечного перерізу каналу. Експеримент з капілярами різних розмірів показав, щуо виявлена в візуальних дослідження довжина хвилі структури потоків, формує також відхилення висоти капілярного підняття води від середнього значення більш ніж на 10\%. Проведені експерименти показали, щзо відхилення параметрів швидкості, коефіиієнта гідравлічного тертя, коефіиієнта тепловіддачі, висоти капілярного підйому води від усереднених значень для заданої величини початкового тиску при зміні поперечних розмірів проточних частин має хвильовий характер зі стійким розміром довжини хвилі.
\end{abstract}

Ключові слова: структура потоку, турбулентність, візуалізація, ламінарний режим, коефіцієнт тертя, капіляр.

doi: https://doi.org/ 10.15673/ret.v55i3.1577

(C) The Author(s) 2019. This article is an open access publication

This work is licensed under the Creative Commons Attribution 4.0 International License (CC BY) http://creativecommons.org/licenses/by/4.0/

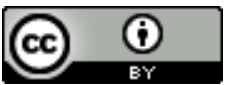

\section{1. Вступ}

Проблема самоорганізації матеріальних систем стає однією 3 центральних проблем науки. 3 одного боку, I. Пригожин формує революційну парадигму: «фізика може описувати структуру різних середовищ як форму адаптації до зовнішніх умов» $[1,2,3] .3$ іншого боку Веліканов М.А. висуває гіпотезу про те, що структура потоків притаманна кожному руху рідин і газів без будьякого впливу зовнішніх причин $[4,5]$. Пошук причин утворення структури розділився на два напрямки: пошуку зовнішніх сил для організації структури або системи, або визнання форми існування матеріальних середовищ 3 властивою цим системам самоорганізацією когерентних або дискретних утворень, стійких у просторі та часі.
Синергетичний підхід до вивчення природних процесів структуроутворення може дозволити вирішити питання, яке «мучило» засновників термодинаміки: чому всупереч тенденції зростання ентропії, яка характеризує прагнення матеріальних систем до стану хаосу, світ, що оточує нас, демонструє високу ступінь організації і порядку. У другій половині ХХ століття виявленню структури при русі рідин і газів приділяється все більше уваги. Найчастіше дослідження спрямовані на виявлення і дослідження резонансної взаємодії між поверхнями і внутрішніми хвилями в рідині або газі $[6,7]$. Однак, сучасні уявлення про рух рідин і газів залишаються на понятті турбулентність як складній, неврегульованій в часі і просторі (хаотичній) поведінці дисипативних середовищ, яка не може бути відтво- 
рена або описана при як завгодно точному завданні начальних і граничних умов. Традиційні рівняння, що описують ламінарні і турбулентні течії, забезпечують розрахунок тільки усереднених параметрів потоків: швидкості, тиску, густини і температури. Застарілі уявлення про хаос турбулентності $є$ перешкодою для розвитку різного енергетичного обладнання.

\section{2. Структура потоків і її вплив на гідравлічні процеси}

Традиційні уявлення про рух рідини і газів зводяться до осереднення в часі реальних параметрів хаотичної структури потоків. Так на рисунку 1 представлено епюри усереднених величин швидкостей $V$ і напруг $\tau$ в поперечному перерізі каналу при ламінарній течії.

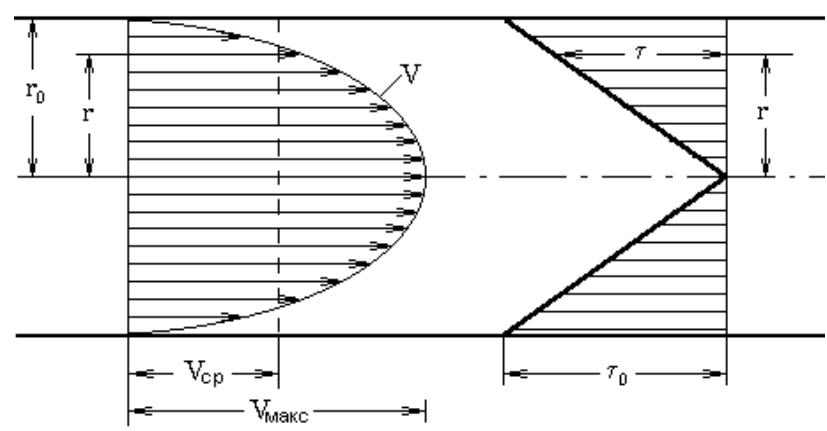

Рисунок 1 - Епюри швидкостей і напруг ламінарного потоку, побудовані на основі усереднених параметрів

Численні дослідження руху рідин за останні 40 років показали, що потоки істотно детерміновані і мають організовану структуру, яка має суттєвий вплив на різні характеристики потоків.

Проведені авторами візуальні дослідження ламінарного струменя виявили поперечну структуру потоку у вигляді ліній різної оптичної густини (ступеня сірого). Візуальні дослідження структури ламінарного струменя наочно демонструють темні і світлі лінії вздовж потоку.

Відповідно до опису методу візуалізації дискретних структур потоків (МВДСП) із використанням оптично-активної рідини - світлі лінії відповідають величині реальної швидкості більшої, ніж усереднена швидкість в даній області. I навпаки, темні лінії відповідають швидкості меншій, ніж усереднена швидкість в даній області потоку [8, 9].

Регулярність чергування смуг і стійкість ї розмірів служить підтвердженням правильності визначення ламінарного режиму як шаруватої течії, де шари з різною величиною швидкості не перемішуються. Тобто, ми бачимо структуру потоку як стійку систему розподілу параметрів. Візуальні картини можна розглядати як «систему» або «ціле» 3 регулярною організацією «еле- ментів» або «частин» у вигляді структури. Відповідно до одного з визначень Аристотеля: «ціле за своєю суттю включає в себе більше, ніж міститься в простій сумі складових його часТин» [10].

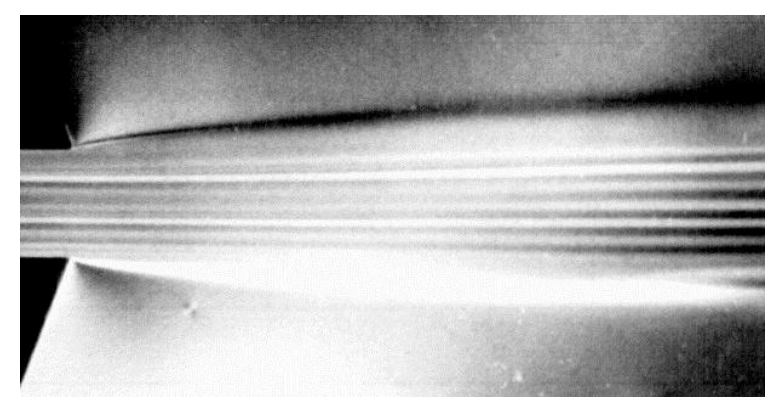

$\mathrm{a}$

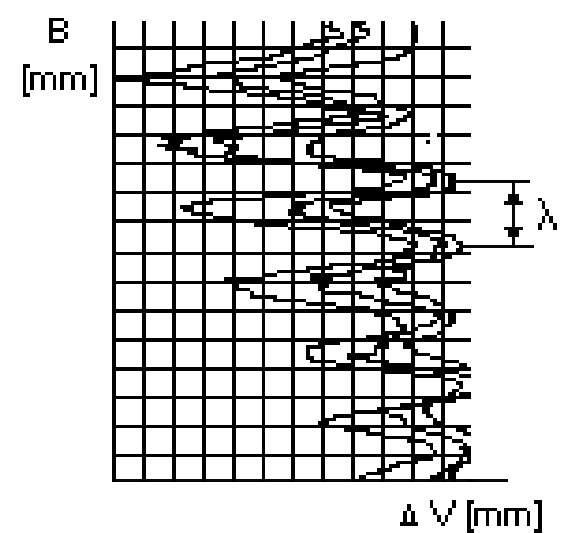

6

Рисунок 2 - Структура ламінарного струменя $\operatorname{Re}=1700:$

a) фрагмент структури ламінарного струменя; б) розподіл оптичної густини.

$B$ - иирина каналу; $\Delta V$-градієнти швидкості;

$\bar{\lambda}$ - довжина хвилі зміни величин пульсачійних компонент швидкості.

Характер зміни оптичної густини в світлих і темних смугах (рис. 2.б) свідчить про хвильовий характер розподілу градієнтів швидкості) в поперечному перерізі потоку з параметром довжини хвилі $\bar{\lambda}$. Використовуючи результати візуальних досліджень потоків, був проведений гідравлічний експеримент 3 метою виявлення впливу структури потоків на коефіцієнт гідравлічного тертя $\lambda$. Сьогодні вважається, що коефіцієнт гідравлічного тертя $\lambda$ залежить від числа Рейнольдса Re і шорсткості $\Delta$.

$$
I_{f}=f(\operatorname{Re}, \Delta) \text {. }
$$

Для проведення гідравлічного експерименту було розроблено моделюючий пристрій $з$ прямокутними щілинними каналами $і$ абсолютно гладкою поверхнею, причому в каналах змінювалася тільки їх висота $L$. 
Стійкий характер розподілу поперечних структур потоків дозволив розробити і провести ряд експериментів, які підтверджують вплив поперечних структур на гідравлічні параметри та енергетичні характеристики (коефіцієнт тепловіддачі) при русі рідин і газів.

\section{3. Структура відображає хвильовий характер зміни параметрів потоку}

Проведено дослідження залежності коефіцієнта гідравлічного тертя $\lambda_{\mathrm{f}}$ від числа Рейнольдса $\operatorname{Re}$ в прямокутних каналах з відполірованою поверхнею. В експерименті використовувалася модель каналу з однаковою шириною $b$ i довжиною $l$, змінювалася тільки висота каналу $h$ в діапазоні $h=0,9-2,55 \mathrm{MM}$.

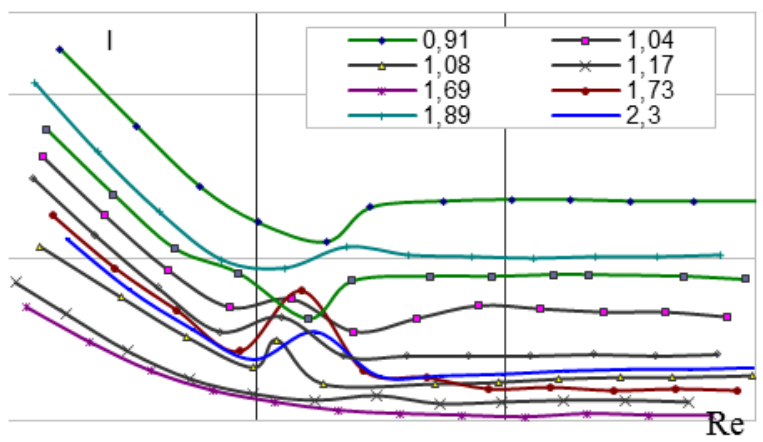

Рисунок 3 - Залежність $\lambda_{f}=f(L ; \operatorname{Re})$ при зміні висоти щілинних каналів

Значення коефіцієнтів гідравлічного тертя для таких моделей повинні бути рівні значенням, знайденим за формулою Блазіуса. Розраховані за експериментальними даними значення коефіцієнтів гідравлічного тертя $\lambda$ для різних величин висоти каналів відрізнялися від розрахованих за формулою Блазіуса.

В діапазоні зміни висоти каналів $L=0,9-$ 2,55 мм для декількох розмірів коефіцієнт тертя був на $7 \div 21 \%$ більше, а для інших розмірів на $9 \div 17 \%$ менше, ніж розраховані за формулою Блазіуса, причому характер зміни величини тертя відповідає зміні довжини хвилі $\bar{\lambda}$ поперечних структур потоку на рисунку 1.

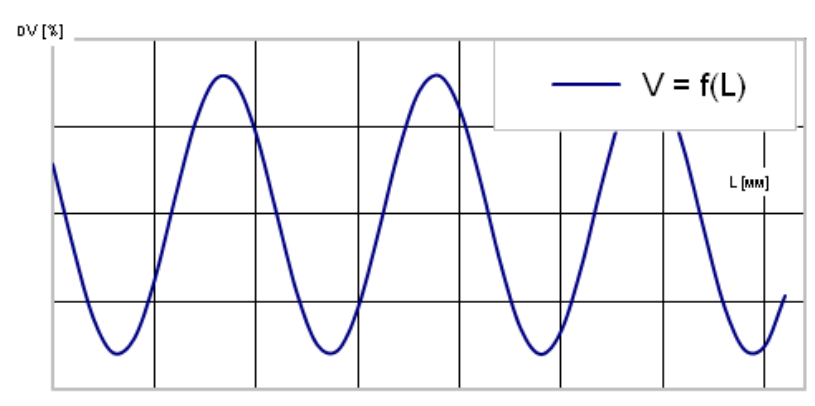

Рисунок 4 - Характер зміни пульсаиійної компоненти швидкості $\Delta V$
Таким чином експеримент показав, що коефіцієнт гідравлічного тертя $\lambda_{f}$ при заданих початкових параметрах залежить не тільки від числа Рейнольдса $\operatorname{Re}$ i шорсткості $\Delta$, але також залежить від геометричних поперечних розмірів каналу $L$. Причому хвильовий характер зміни коефіцієнта гідравлічного тертя при лінійній зміні розмірів каналів в проведених експериментальних дослідженнях відповідає розмірам смуг на візуальних картинах структури струменя.

$$
I_{f}=f(\operatorname{Re}, \Delta, L) .
$$

Запропонована модель обгрунтування отриманих результатів заснована на моделі осереднення Рейнольдса, узгоджується зі вже відомими даними: про хвильовий характер епюри пульсаційної швидкості в граничному шарі; регулярних сплесках в граничному шарі; відомими висновками, що 5\% турбулентного граничного шару біля стінки генерують понад 50\% турбулентної енергії потоку.

Поперечні структури можуть бути використані при проектуванні проточних частин щілинних каналів водно-випарних охолоджувачів повітря. Непарна кількість півхвиль відповідає позитивному впливу поперечних структур, парна кількість півхвиль - дисипативному впливу. У роботах $[3,5]$ запропонована гіпотеза про вплив структур потоків на енергетичні характеристики проточних частин. Запропоновано формулу визначення оптимального розміру поперечного перерізу каналу $L$, що забезпечує мінімальну величину гідравлічного опору і відповідно максимальну величину швидкості потоку:

$$
L=n \bar{\lambda}+0,25 \bar{\lambda},
$$

де $\bar{\lambda}$ - довжина хвилі зміни пульсаційних компонент швидкості; $n$ - кількість хвиль, що укладаються в поперечному перерізі каналу.

При розмірі каналу $L$, розрахованого за формулою (3), рівному кратному числу довжин хвиль плюс чверть довжини хвилі, величина гідравлічного опору буде мінімальною, а величина швидкості для заданого значення початкового тиску буде максимальною на 8-16\% більше усередненого значення.

При розмірі каналу $L$ рівному кратному числу довжин хвиль плюс три чверті довжини хвилі, величина гідравлічного опору буде максимальною i, відповідно, максимальна величина швидкості потоку буде мінімальною:

$$
L=n \bar{\lambda}+0,75 \bar{\lambda} \text {. }
$$

До традиційних уявлень про параболічний закон розподілу усереднених значень швидкостей (див. рис.1) необхідно додати виявлений хвильовий характер розподілу пульсаційного компоненту швидкості. Підсумовування епюри 
усереднених значень швидкості течії в кожній точці потоків з хвильовим характером розподілу пульсаційних компонент швидкості дає епюру реальних значень швидкості в кожній точці поперечного перерізу каналу.

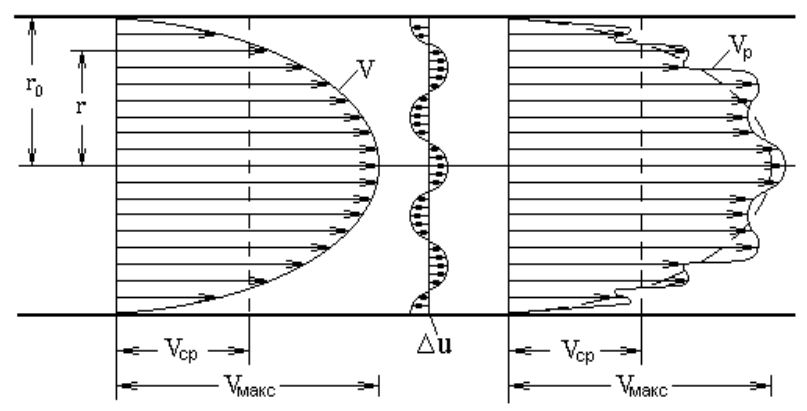

Рисунок 5 - Епюри усереднених і реальних швидкостей ламінарної течї

Таким чином, отримані результати дозволили підтвердити гіпотезу Веліканова М. А. про те, що структура потоку притаманна кожному руху рідин і газів без будь-якого впливу зовнішніх причин. Експериментальні дослідження процесів руху рідин і газів показали можливість використання позитивного або дисипативного впливу структури потоків на характеристики обладнання.

\section{4. Вплив структури потоків на капілярне під- няття води}

Для дослідження впливу поперечних розмірів капілярів на висоту підняття води був проведений спеціальний експеримент. На рисунку 6 показано спеціальний моделюючий пристрій, де можна закріплювати листи різної товщини з вирізаним каналом однакових розмірів.

Відомо, що дрібнопористі тверді тіла добре змочуються і мають досить велику висоту капілярного підняття води - до 200 міліметрів. Для дослідження капілярних властивостей твердих поверхонь були проведені дослідження капілярного підняття води між двома пластинами.

Відома формула капілярного підняття води $h$ в каналах з прямокутним перерізом

$$
h=15 / s \text {. }
$$

Для дослідження залежності (5) було виготовлено моделюючий пристрій, який являє собою тонкий лист пластмаси з вирізаним капілярним каналом, жорстко закріплений між двома відполірованими покривними плитами з оргскла. Для проведення досліду були виготовлені 9 листів із заданими розмірами - товщини листа $s$ і шириною вирізаного каналу $b$ різної товщини $s=$ $=0,1 \div 2$ мм. Для забезпечення однакової ширини $b=3$ мм = const проточна частина каналу виконувалася фрезеруванням всіх листів одночасно.

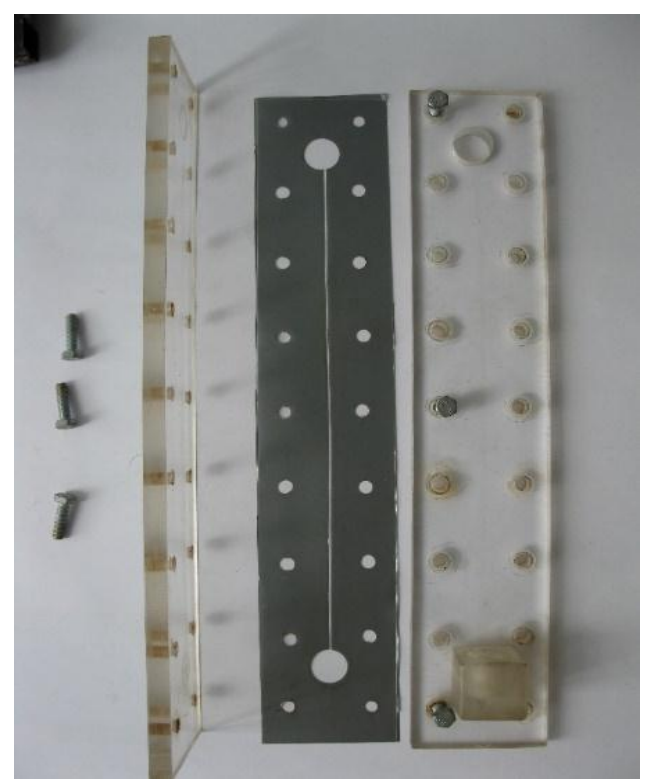

Рисунок 6 -Моделюючий пристрій для дослідження впливу капілярного підняття води

Аналіз результатів експерименту показав, що зміна висоти капілярного підняття також має хвильовий характер 3 довжиною хвилі $\bar{\lambda}$. Відхилення висоти капілярного підняття відрізняється від середнього значення, розрахованого за формулою (5), більш ніж на 10\%.

Таким чином при нормальних умовах лінійній зміні поперечних розмірів капілярів відповідає хвильовий характер зміни висоти капілярного підняття, що дозволяє розробляти структуру пористих поверхонь для охолоджувачів повітря 3 урахуванням закономірностей організації структури потоків.

Відхилення від формули (5)

$$
h=\frac{B}{s} \sin 2 \pi \frac{s}{\lambda},
$$

де $B=$ ширина капілярного каналу.

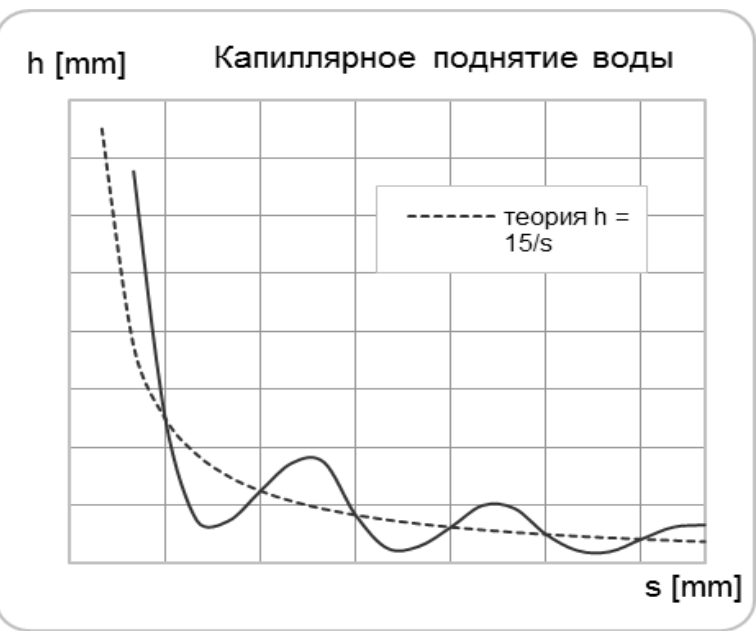

Рисунок 7 - Зміна висоти підняття води в моделі капілярних каналів 
Реальна висота капілярного підняття води може бути розрахована за формулою, в якій буде врахована залежність хвильового характеру розподілу структури води.

$$
h=\frac{A}{s}+\frac{B}{s} \sin 2 \pi \frac{s}{\lambda} .
$$

Нанесення на пористу поверхню вертикальних каналів з поперечними розмірами, розрахованими за формулою (3) підвищує капілярний ефект підняття води. Експерименти нанесення каналів на капілярно-пористі пластини показали, що при розмірах капілярних каналів на пластині 3 урахуванням структури води висота підняття води збільшується від $h=50$ мм до $h=140 \mathrm{мм}$.

Отримані результати підтверджують відповідність виявленої структури потоків води результатам гідравлічних експериментів по дослідженню величини коефіцієнта гідравлічного тертя $\lambda_{f}$ і коефіцієнта тепловіддачі $\alpha$ в щілинних каналах [11]. Діапазон зміни коефіцієнта дозволяє піти від невизначеності розрахунку втрат напору в каналах 3 малими розмірами. Характер зміни висоти капілярного підняття води, розрахованої за формулою (5), повинен враховувати хвильовий характер розподілу структури води

\section{5. Висновки}

Виявлення структури рідин і газів відкриває можливості формування нового рівня параметрів i характеристик енергетичного обладнання і систем різного виду і призначення. Нова інформація про структуроутворення змінює парадигму, засновану на базових моделях суцільного середовища, в сторону моделей структурування і вдосконалення властивостей різних середовищ.

Проведені дослідження дозволили зробити висновок, що одним з факторів, що впливають на механізми формування структури потоків, $€$ їх геометричні параметри. Тому формування структури потоків за рахунок вдосконалення проточних частин відкриває нові перспективи розробки енергетичного устаткування і систем.

Проведені експерименти, а також аналіз відомих наукових результатів показали, що відхилення параметрів швидкості $V$, коефіцієнта гідравлічного тертя $\lambda_{\mathrm{f}}$, коефіцієнта тепловіддачі $\alpha$,

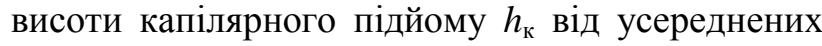
значень для заданої величини початкового тиску $P_{\text {н }}$ при зміні поперечних розмірів проточних частин має хвильовий характер $з$ довжиною хвилі $\bar{\lambda}$.
Аналіз експерименту показав, що зміна величин $\lambda_{\mathrm{f}}$ має хвильовий характер 3 довжиною хвилі $\bar{\lambda}$. Відхилення величини коефіцієнта гідравлічного тертя $\lambda_{\mathrm{f}}$ від середнього значення при $\operatorname{Re}>6000$ становить понад 10\%, при $\operatorname{Re}<3500$ відхилення понад 15\%. При цьому для заданої

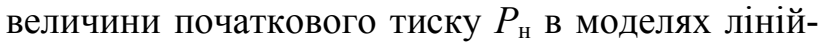
ній зміні розмірів $L[\mathrm{Mм}]$ відповідає хвильовий характер зміни швидкості (розрахованої за вимірюваною витратою).

\section{Література}

1. Пригожин И., Стенгерс И. «Порядок из хаоca». M., 1986. C. 55

2. Пригожин И. Время, хаос, квант/ И. Пригожин, И. Стенгерс. - М.: Прогресс, 1994. - 272 с.

3. Выровой В.Н. Системный подход при анализе структуры строительных конструкций / В.Н. Выровой. А.В. Дорофеев. В.Г. Суханов // Ресурсоекономні матеріали, конструкції, будівлі та споруди. -Рівне, 2008. - Вип.41. - Ч. 1. - С. 133-139.

4. Великанов М.А. Динамика русловых потоков: т. 2. - М.: Стройиздат, 1954. - 280 С.

5. Филлипс О. Взаимодействие волн - эволюция идеи. - Современная гидродинамика. Успехи и проблемы. М.: Мир. 1984. С. 297-314.

6. Basin M. Vortex-wave Resonance. Paper, Presented on the 2 International Nonlinear Science Conference. Heraklion. Greece. March 11-12 2006.

7. Басин М.А. Волновой и структурный резонанс. Возникновение и особенности // Международная научная конференция: «Идеи синергетики»- Твер. гос. ун-т. 2006. С. 108-114.

8. Maisotsenko V. S., Arsiri V. A. Method of determining for working media motion and designing flow structures for same // PST 5.812.423 USA 3/4 Publ. - 1998.

9. Arsiri V. Reconstruction of turbomachines on the basis of the flow structure visual diagnostics / Arsiri V., Kravchenko O. // International Journal Mechanics and Mechanical Engineering, 2018. Volume 22. Number 2, P. 405-414

10. Аристотель. Соч. в 4 т. Т. 1. М., 1975. С. 174175.

11.Кожелупенко Ю.Д. Экспериментальные исследования теплоотдачи и гидравлического сопротивления при однофазном течении воды в щелевых каналах. / Ю.Д. Кожелупенко, А.Л. Коба // Холодильная техника и технология, 2002. № 4 (78), c. 40-47.

Отримана в редакції 04.05.2019, прийнята до друку 07.06.2019 


\title{
The influence of the structure on the distribution of flow parameters and capillary rise of water
}

\author{
V. A. Arsiri ${ }^{\text {I }}$, V. F. Isaev, P. M. Ryabokon, B. D. Savchuk \\ Odessa State Academy of Construction and Architecture, st. Didrichson, 4, Odessa, 65029, Ukraine \\ 1) $\triangle$ e-mail: arsiri.v.a@opu.ua, ORCID ID: https://orcid.org/0000-0003-3617-8487
}

Visual studies of fluid motion revealed a velocity distribution structure in the cross section of the channels. The analysis of two areas of research: the ideas of I. Prigogine search for external forces to organize the structure or system; as well as the hypothesis of M. Velikanov on the recognition of the form of existence of material media with their inherent self-organization of coherent or discrete formations. Revealing the structure of flows that is stable in space and time explains: why the world around us shows a high degree of organization and order in spite of the dominance of the turbulence chaos model and the assertion of an increase in entropy. Hydraulic experiments have proved the influence of the flow structure on the distribution of parameters during the movement of liquids and gases. The hydraulic friction coefficient for given initial parameters depends not only on the Reynolds number and roughness, but also depends on the transverse dimensions of the channel. The wave nature of the distribution of parameters was obtained both under turbulent and laminar flow regimes. The wave nature of the change in the coefficient of hydraulic friction removes the problem of uncertainty in calculating the pressure loss and other energy indicators of the equipment. The research results show the possibility of forming the flow structure during the movement of liquids and gases.To the traditional concept of the parabolic distribution law of the diagram of averaged velocity values, the wave character of the distribution of the pulsation velocity components has been added. Summing the plot of the averaged values of the flow velocity at each point of the flows with the wave nature of the distribution of the pulsating velocity components gives a plot of the real velocity values at each point of the channel cross section. An experiment with capillaries of different sizes showed that the wavelength of the flow structure revealed in visual studies also forms a deviation of the height of the capillary rise of water from the average by more than 10\%. The experiments showed that the deviation of the velocity parameters, the coefficient of hydraulic friction, the heat transfer coefficient, the height of the capillary rise of water from the averaged values for a given value of the initial pressure when changing the transverse dimensions of the flow parts has a wave character with a stable wavelength size.

Keywords: flow structure, turbulence, visualization, laminar regime, friction coefficient, capillary.

\section{References}

1. Prigozhin, I., Stengers, I. (1986) Poryadok iz haosa. Moscow, $55 \mathrm{p}$.

2. Prigozhin, I., Stengers, I. (1994) Vremya, haos, kvant. Moscow, Progress, 272 p.

3. Virovoy, V.N., Dorofeev, A.V., Suhanov V.G. (2008) Sistemnyiy podhod pri analize strukturyi stroitel $\neg$ nyih konstruktsiy. Resursoekonomni materialy, konstruktsii, budevli ta sporudy, 41, 133-139.

4. Velikanov, M.A. (1954) Dinamika ruslovyih potokov, vol. 2, $280 \mathrm{p}$.

5. Fillips, O. (1984) Vzaimodeystvie voln - evoliutsiia idei. Sovremennaia gidrodinamika. Uspekhi i problemy. Moscow, Mir, 297-314.

6. Basin, M. (2006) Vortex-wave Resonance. Paper, Presented on the 2 International Nonlinear Science Conference Heraklion. Greece, March 11-12 2006.

7. Basin, M.A. (2006) Volnovoi i strukturnyi re zonans. Vozniknovenie i osobennosti. Idei sinergetiki, 108-114.

8. PST 5.812.423 USA Maisotsenko V.S., Arsiri V.A. Method of determining for working media motion and designing flow structures for same. Publ. 1998.

9. Arsiri V., Kravchenko O. (2018) Reconstruction of turbomachines on the basis of the flow structure visual diagnostics. International Journal Mechanics and Mechanical Engineering, 22(2), 405-414.

10. Aristotel. (1975) Vol. 1. Moscow, pp. 174-175. 11. Kozhelupenko, Yu.D., Koba, A.L. (2002) Eksperimentalnyie is-sledovaniya teplootdachi i gidravlicheskogo soprotivleniya pri odnofaznom techenii vodyi v schelevyih kanalah. Refrigeration engineering and technology, No 4(78), 40-47.

Received 04 May 2019

Approved 07 June 2019

Available in Internet 30 June 2019 